\title{
Determinantes e Condições de Saúde Bucal em Crianças e Adolescentes com Necessidades Especiais
}

\section{Determinants and Oral Health Care Conditions in Children and Adolescents with Special Needs}

\author{
Ellem Fabiola Caregnato ${ }^{1}$ \\ Laura Stieven Simonatto ${ }^{1}$ \\ Deison Alencar Luciett ${ }^{2}$
}

\section{RESUMO}

A saúde bucal de indivíduos com necessidades especiais depende em grande parte dos pais, dos responsáveis e de cuidados oferecidos em serviços educacionais e de saúde. Objetivo: descrever os hábitos alimentares, os cuidados em saúde bucal e o índice CPO-D de crianças e adolescentes matriculados nas APAEs dos Municípios de São Domingos/ $\mathrm{SC}$ e Xaxim/SC. Resultados: Participaram da pesquisa todos os 35 alunos com idades entre 5 e 17 anos, com Síndrome de Down, Síndrome do X-frágil, Síndrome de West e Paralisia Cerebral. Foram utilizados questionários direcionados aos pais ou responsáveis e realizados exames bucais para verificar biofilme visível e o ataque da doença cárie. Foi identificado que existe grande preferência por alimentos e bebidas doces e elevado consumo após ou entre as refeições. Os pais relataram dificuldades para realizar a higiene bucal. Ocorreram limitações no uso do fio dental e no número e qualidade das escovações, comprovados pela grande quantidade de biofilme em todos os examinados. O CPO-D na faixa dos 12 aos 17 anos variou de 0 a 7, com média de 3,3. Conclusão: Os achados apontam para a necessidade de abordagem conjunta entre os familiares, os pacientes, as escolas e os serviços odontológicos com vistas à promoção de melhores condições de saúde bucal às crianças e adolescentes com necessidades especiais.

DESCRITORES: Saúde bucal, Criança excepcional, Higiene bucal, Hábitos alimentares. Índice CPO. Pais.

\begin{abstract}
The oral health of individuals with special needs depends on the parents, caregivers and care offered in educational and health services. Objetive: this study aimed to describe eating habits, oral health care and the DMFT index of children and adolescents enrolled in APAEs in the cities of São Domingos / SC and Xaxim / SC. Results: All 35 students aged 5 to 17 years with Down Syndrome, X-Fragile Syndrome, West Syndrome and Cerebral Palsy participated in the study. Questionnaires were used to address parents or guardians and oral examinations were performed to verify visible biofilm and the attack of caries disease. It has been identified that there is great preference for food and sweet drinks and high consumption after or between meals. Parents reported difficulties in performing oral hygiene. There were limitations in the use of dental floss and in the number and quality of the brushings, as evidenced by the large amount of biofilm in all the examined individuals. DMFT index in the 12 to 17 age range ranged from 0 to 7 , with an average of 3.3. Conclusion: The findings point to the need for a joint approach among families, patients, schools and dental services with a view to promoting better oral health conditions for children and teenagers with special needs.
\end{abstract}

DESCRIPTORS: Oral health, Exceptional Child, Oral Hygiene, Food Habits, DMF Index, Parents.

1 - Cirurgiã-Dentista, Universidade Comunitária da Região de Chapecó

2 - Professor do Curso de Odontologia, Faculdade Especializada na Área de Saúde do Rio Grande do Sul. 
D eficiências podem ser parte ou uma expressão de uma condição de saúde, mas não indicam, necessariamente, a presença de uma doença ou que o indivíduo deva ser considerado doente. Por isso, devem ser consideradas da mesma forma que se faz com as outras potencialidades humanas ${ }^{1,2}$.

Contudo, independente da forma e como acometem, elas interferem tanto na rotina desses pacientes, quanto no cuidado a saúde ${ }^{3}$. Portadores de transtornos mentais e/ou comportamentais, devido ao comprometimento intelectual e motor, tem a sua higiene bucal precária ${ }^{4}$.

Apesar do declínio da doença cárie dental observado nos últimos levantamentos epidemiológicos de saúde bucal em nível nacional ${ }^{5,6}$, as condições de saúde bucal de pacientes portadores de necessidades especiais merece atenção ${ }^{7,8}$.

Considerando a múltipla interação de fatores no desenvolvimento das doenças bucais, é importante adotar medidas preventivas como remoção regular do biofilme dental, redução do consumo de açúcares livres, acesso ao flúor e aos serviços odontológicos, além daquelas voltadas aos modos e condições de vida de comunida$\operatorname{des}^{9,10}$.

A manutenção das condições de higiene bucal em pacientes com necessidades especiais é uma tarefa difícil ${ }^{11-14}$, em face desses pacientes serem muitas vezes dependentes para as atividades de vida diária, como a alimentação e a higiene bucal.

Portadores de transtornos mentais e/ou comportamentais, devido ao comprometimento intelectual e motor, tem a sua higiene bucal precária ${ }^{4}$. Dessa forma, entende-se como necessário a participação ativa de um familiar ou responsável que atue como cuidador, formal ou informal, para realizar e manter a saúde bucal.

Os cuidadores também precisam ter em mente que suas atitudes, seus hábitos e costumes podem influenciar seus filhos que podem adotar os mesmos comportamentos ${ }^{15}$, por isso, é impor- tante a formação de hábitos saudáveis tanto para o cuidador quanto para a criança.

Considerando esses aspectos, este estudo teve como objetivo descrever os hábitos alimentares, os cuidados em saúde bucal e o índice CPO-D de crianças e adolescentes com necessidades especiais matriculados nas Associações de Pais e Amigos dos Excepcionais (APAE) em dois pequenos Municípios do interior no Estado de Santa Catarina, onde ainda não existiam tais informações.

\section{Metodologia}

Tratou-se de estudo epidemiológico descritivo observacional transversal, também denominado estudo de prevalência. A pesquisa foi realizada em conjunto com as APAEs das Cidades de São Domingos e Xaxim, do Estado de Santa Catarina, Brasil, durante o segundo semestre de 2014. Essas escolas foram selecionadas em função da possibilidade de acesso às instituições.

A pesquisa seguiu todas as recomendações da Resolução CNS N 466/2012, sendo aprovada pelo Comitê de Ética em Pesquisa da Unochapecó por meio do Parecer №. 172/14.

Foram incluídos todos os alunos regularmente matriculados na Escola Especial Hilda Lago Dallacorte (São Domingos/SC) e na Escola Especial Marlene Stieven (Xaxim/SC) com idades entre 5 e 18 anos.

A coleta de dados foi realizada ao longo de quatro semanas e envolveu a realização de exames bucais e aplicação de questionários. Inicialmente, a pesquisa foi apresentada aos pais, para esclarecimento sobre os procedimentos, durante reuniões regulares das escolas.

Previamente, aos exames bucais foi realizada a calibração por meio do uso de imagens. O exame clínico foi realizado nas próprias escolas, em sala de aula, sob boa iluminação e com o auxílio de espátulas de madeira. Todos foram realizados pela mesma examinadora com uso 
de equipamento de proteção individual completo (gorro, máscara, óculos, jaleco de tecido e luvas) e materiais para o gerenciamento de resíduos. Foi utilizada uma ficha para registro clínico adaptada ${ }^{16}$, envolvendo variáveis demográficas, diagnóstico da síndrome, presença de biofilme visível e Índice CPO-D.

Após o exame, foi aplicado um questionário sobre condições socioeconômicas, conhecimentos e práticas sobre higiene bucal e hábitos alimentares. O questionário foi aplicado aos pais ou responsáveis pelas crianças e adolescentes participantes. Para tanto, foram obtidos os endereços das famílias junto às APAEs e realizadas visitas a cada um dos domicílios.

Os dados coletados foram tabulados para o Programa Microsoft Office Excel (2007) e posteriormente analisados estatisticamente por meio do Programa Statistical Package for Social Sciences (SPSS) versão 12.0. A análise dos dados, de caráter descritivo, foi expressa por médias, porcentagens e distribuição das variáveis.

\section{Resultados}

Todos os pais $(n=35-100 \%)$ responderam aos questionários, fornecendo informações sobre variáveis socioeconômicas, condição de saúde, hábitos alimentares e de higiene bucal dos seus filhos. Participaram dos exames bucais todos os alunos devidamente matriculados nas APAEs de São Domingos/SC e Xaxim/SC ( $n=35$ - 100\%). Para fins de CPO-D, foram considerados indivíduos com idades entre 12 e 17 anos de idade $(n=20)$.

\section{Condições de moradia da família}

A maioria dos alunos residia com os pais $(n=26-74,3 \%)$. Desses, $n=17(48,6 \%)$ também moravam com irmãos. Dois alunos $(5,7 \%)$ viviam sob responsabilidade dos avós e outros sete $(20,0 \%)$ com outros familiares (Tabela 1$)$.
Identificou-se que a maior parte dos alunos $(n=31-88,6 \%)$ tinha, pelo menos mais um irmão ou irmã. Quatro alunos (11,4\%) eram filhos únicos ou possuíam quatro ou mais irmãos. Quanto ao número de moradores do domicílio verificou-se predomínio de ambientes com quatro moradores $(n=15-42,9 \%)$ ou cinco ou mais moradores $(n=14$ - 40,0\%). Dois alunos (5,7\%) residiam apenas com o seu responsável (Tabela 1$)$.

Quanto à disponibilidade de produtos para a higiene bucal no domicílio, constatou-se que todos ( $n=35-100 \%$ ) possuíam escova de dentes própria. Entretanto, parcela considerável ( $n=11$ $31,4 \%$ ) não dispunha de fio dental na residência (Tabela 1).

\section{Características dos alunos}

Foram examinados 22 alunos (62,9\%) na cidade de Xaxim/SC e $13(37,1 \%)$ em São Domingos/SC. As idades variaram de 5 a 17 anos de idade, sendo a média de 10,8 anos. Houve predominância do sexo masculino ( $n=20,57,1 \%)$ em relação ao feminino ( $n=15,42,9 \%)$.

Com relação à caracterização das condições especiais de saúde ( $n=35$ - 100\%), constatou-se predominância de paralisia cerebral $(n=22$ - 62,9\%), seguida das Síndromes de Down ( $n=8$ - 22,9\%), do X-Frágil ( $n=4-11,4 \%)$ e de West $(n=1$ - 2,8\%). Constatou-se que houve maior número de escolares em todas as síndromes, exceto do X-Frágil, no Município de Xaxim/SC.

\section{Hábitos alimentares dos alunos}

De acordo com os pais ou responsáveis, a maioria dos alunos realizava quatro ou mais refeições diárias ( $n=30-85,7 \%)$ sendo que $17(48,6 \%)$ faziam quatro e outros $13(37,1 \%)$ cinco ou mais refeições. Dois alunos (5,7\%) tinham apenas duas refeições por dia (Tabela 2 ).

A maioria $(n=22,62,9 \%)$ relatou que os alunos gostavam de alimentos doces e guloseimas. 
Tabela 1- Caracterização socioeconômica da família segundo os pais ou responsáveis

\begin{tabular}{l|c|c}
\hline \multicolumn{1}{c|}{ Variáveis } & $\mathrm{n}$ & $\%$ \\
\hline Com que mora a criança ou adolescente? & 17 & 48,6 \\
Mãe e/ou pais e irmãos & 9 & 25,7 \\
Mãe e/ou pai apenas & 7 & 20,0 \\
Com outros familiares & 2 & 5,7 \\
Com avós apenas & 35 & 100 \\
Total & 4 & \\
\hline No total, quantos filhos você tem? & 12 & 11,4 \\
Um & 7 & 34,3 \\
Dois & 8 & 20,0 \\
Três & 4 & 22,9 \\
Quatro & 35 & 11,4 \\
Cinco ou mais & & 100 \\
Total & 2 & \\
\hline Quantas pessoas, incluindo você, moram na sua casa? & 4 & 5,7 \\
Duas pessoas & 15 & 11,4 \\
Três pessoas & 14 & 42,9 \\
Quatro pessoas & 35 & 40,0 \\
Cinco ou mais pessoas & & 100 \\
Total & - & - \\
\hline Todos que moram na sua casa têm escova de dente? & 35 & 100,0 \\
Não & 35 & 100 \\
Sim & & \\
Total & 11 & 31,4 \\
\hline Vocês têm fio dental em casa? & 24 & 68,6 \\
Não & 35 & 100 \\
Sim & & \\
Total & & \\
\hline
\end{tabular}

Fonte: Dos autores, 2017.

Contudo, 19 indivíduos (54,3\%) não costumavam ingerir ou raramente ingeriam doces. Daqueles que informaram consumir doces ( $n=16-45,7 \%)$, a maioria o fazia entre as refeições $(n=11-31,4 \%)$ (Tabela 2).

Verificou-se que grande parte dos alunos $(n=25-71,4 \%)$ gostava de bebidas doces, sendo o seu principal consumo ( $n=16-45,7 \%)$ logo após as refeições. Contudo, 13 alunos $(37,1 \%)$ não costumavam ingerir ou raramente ingeriam bebidas doces (Tabela 2).

A maior parte dos pais ou responsáveis $(n=20-57,2 \%)$ informou não acrescentar, no dia-a-dia, açúcares aos alimentos ou bebidas consumidos pelos seus filhos, sejam aqueles industrializados ou preparados a partir de frutas, vegetais ou leite. Contudo, 11 indivíduos $(31,4 \%)$ costumavam acrescentar açúcares (Tabela 2).

\section{Hábitos de higiene bucal}

De acordo com as informações dos pais ou responsáveis, todos os 35 alunos possuíam escova de dentes própria em casa, porém um aluno $(2,9 \%)$ não escovava os dentes todos os dias. Constatou-se que cinco estudantes $(14,3 \%)$ realizavam apenas uma e outros $10(28,6 \%)$ duas escovações diárias. A maioria ( $n=17-48,5 \%)$ revelou que os escolares realizavam três escovações por dia. Contudo, segundo 32 pais ou responsáveis 
Tabela 2- Hábitos alimentares dos alunos segundo os pais ou responsáveis

\begin{tabular}{l|c|c}
\multicolumn{1}{c|}{ Variáveis } & $\mathbf{n}$ & $\mathbf{\%}$ \\
\hline Em média, quantas refeições por dia seu filho costuma & & \\
fazer? & 2 & 5,7 \\
Duas refeições & 3 & 8,6 \\
Três refeiç̃̃es & 17 & 48,6 \\
Quatro refeições & 13 & 37,1 \\
Cinco ou mais refeições & 35 & 100 \\
Total & 13 & 37,1 \\
\hline Seu filho gosta de doces e guloseimas? & 22 & 62,9 \\
$\quad$ Não & 35 & 100 \\
Sim & & \\
Total & 19 & 54,3 \\
\hline Em qual horário seu filho costuma ingerir doces? & 5 & 14,3 \\
Raramente ou não consome & 11 & 31,4 \\
Logo após as refeições & 35 & 100 \\
Entre as refeições & 10 & 28,6 \\
Total & 25 & 71,4 \\
\hline Seu filho gosta de bebidas doces? & 35 & 100 \\
$\quad$ Não & & 37,1 \\
Sim & 13 & 45,7 \\
Total & 16 & 17,2 \\
\hline Qual horário costuma ingerir bebidas doces? & 6 & 100 \\
$\quad$ Raramente ou não consome & 35 & \\
Logo após as refeições & & 57,2 \\
Entre as refeições & 20 & 11,4 \\
Total & 4 & 31,4 \\
\hline Você costuma acrescentar açúcar nos alimentos e & 11 \\
bebidas do seu filho? & 35 & \\
Nunca & & \\
Às vezes & & \\
Sempre & & \\
Total & & \\
\hline
\end{tabular}

Fonte: Dos autores, 2017.

$(91,3 \%)$ o ideal seria que fossem realizadas três escovações (Tabela 3).

Apenas 12 respondentes (34,3\%) informaram que as crianças e adolescentes utilizavam o fio dental diariamente. Desses indivíduos, a maioria $(n=9-75,0 \%)$ relatou que ele era utilizado uma vez ao dia. Entretanto, para 13 indivíduos $(37,1 \%)$ seria necessário utilizá-lo três vezes ao dia, seguidos de uma vez ( $n=12-34,3 \%)$, duas vezes $(n=8-22,9 \%)$ e quatro ou mais vezes ( $n=2-5,7 \%$ ) (Tabela 3$)$.

Quando questionados sobre o responsável pela escovação, identificou-se que as principais responsáveis pela higiene bucal eram as mães $(n=25-71,4 \%)$. Em relação à fonte de informações sobre como proceder aos cuidados de saúde bucal, verificou-se grande importância para o cirurgião-dentista ( $n=27$ - 77,1\%). Mesmo assim, três indivíduos $(8,6 \%)$ relataram não ter recebido nenhuma instrução a respeito (Tabela 3).

\section{Condições de saúde bucal dos alunos: biofil- me e índice CPO-D}

No exame clínico observou-se que os 35 alunos (100\%) possuíam biofilme visível. Constatou-se grande quantidade de biofilme principalmente na região de incisivos inferiores. 
Tabela 3- Hábitos de higiene bucal dos alunos segundo os pais ou responsáveis

\begin{tabular}{|c|c|c|}
\hline $\begin{array}{l}\text { Variáveis } \\
\end{array}$ & $\mathbf{n}$ & $\%$ \\
\hline $\begin{array}{l}\text { Seu filho tem escova de dentes própria em casa? } \\
\text { Não } \\
\text { Sim } \\
\text { Total }\end{array}$ & $\begin{array}{c}- \\
35 \\
35\end{array}$ & $\begin{array}{c}- \\
100 \\
100\end{array}$ \\
\hline $\begin{array}{l}\text { Seu filho escova os dentes todos os dias? } \\
\text { Não } \\
\text { Sim } \\
\text { Total }\end{array}$ & $\begin{array}{c}1 \\
34 \\
35\end{array}$ & $\begin{array}{c}2,9 \\
97,1 \\
100\end{array}$ \\
\hline $\begin{array}{l}\text { Quantas vezes por dia seu filho escova os dentes? } \\
\text { Não escova todos os dias } \\
\text { Uma } \\
\text { Duas } \\
\text { Três } \\
\text { Quatro ou mais } \\
\text { Total }\end{array}$ & $\begin{array}{c}1 \\
5 \\
10 \\
17 \\
2 \\
35\end{array}$ & $\begin{array}{c}2,9 \\
14,3 \\
28,6 \\
48,5 \\
5,7 \\
100\end{array}$ \\
\hline $\begin{array}{l}\text { Quantas vezes você considera necessário escovar os } \\
\text { dentes por dia? } \\
\text { Uma } \\
\text { Duas } \\
\text { Três } \\
\text { Quatro ou mais } \\
\text { Total }\end{array}$ & $\begin{array}{c}1 \\
1 \\
32 \\
1 \\
35\end{array}$ & $\begin{array}{l}2,9 \\
2,9 \\
91,3 \\
2,9 \\
100\end{array}$ \\
\hline $\begin{array}{l}\text { Seu filho utiliza fio dental todos os dias? } \\
\text { Não } \\
\text { Sim } \\
\text { Total }\end{array}$ & $\begin{array}{l}23 \\
12 \\
35\end{array}$ & $\begin{array}{c}65,7 \\
34,3 \\
100\end{array}$ \\
\hline $\begin{array}{l}\text { Quantas vezes por dia seu filho utiliza fio dental? }{ }^{*} \\
\text { Uma } \\
\text { Duas } \\
\text { Três } \\
\text { Quatro ou mais } \\
\text { Total }\end{array}$ & $\begin{array}{c}9 \\
1 \\
2 \\
- \\
35\end{array}$ & $\begin{array}{c}75,0 \\
8,3 \\
16,7 \\
- \\
100\end{array}$ \\
\hline $\begin{array}{l}\text { Quantas vezes você considera necessário usar o fio } \\
\text { dental? } \\
\text { Uma } \\
\text { Duas } \\
\text { Três } \\
\text { Quatro ou mais } \\
\text { Total }\end{array}$ & $\begin{array}{c}12 \\
8 \\
13 \\
2 \\
35\end{array}$ & $\begin{array}{c}34,3 \\
22,9 \\
37,1 \\
5,7 \\
100\end{array}$ \\
\hline $\begin{array}{l}\text { Quem é o responsável pela escovação do seu filho? } \\
\text { Mãe } \\
\text { Pai } \\
\text { Avó } \\
\text { Total }\end{array}$ & $\begin{array}{c}25 \\
7 \\
3 \\
35\end{array}$ & $\begin{array}{l}71,4 \\
20,0 \\
8,6 \\
100\end{array}$ \\
\hline $\begin{array}{l}\text { De quem recebeu informações a respeito dos cuidados } \\
\text { de saúde bucal do seu filho? } \\
\text { Cirurgião-dentista } \\
\text { Professores } \\
\text { Outros pais ou responsáveis } \\
\text { Não recebeu } \\
\text { Total }\end{array}$ & $\begin{array}{c}27 \\
5 \\
- \\
3 \\
35\end{array}$ & $\begin{array}{c}77,1 \\
14,3 \\
- \\
8,6 \\
100\end{array}$ \\
\hline
\end{tabular}

Fonte: Dos autores, 2017. * Refere-se aos que informaram utilizar fio dental. 
Os valores do Índice CPOD dos 12 aos 17 anos $(n=20)$ variaram de $0(n=2-10,0 \%)$ até 7 $(n=5-5,0 \%)$. O valor mais prevalente foi CPOD 4 $(n=6-30,25 \%)$, seguido do CPOD 2 ( $n=4-20 \%)$ (Tabela 4).

A média do CPO-D dos 12 aos 17 anos ( $n=20-100 \%$ ) foi de 3,30, com variações em função do sexo e condição especial de saúde. Em relação ao sexo, identificou-se CPO-D de 3,11 para indivíduos do sexo masculino ( $n=14-70,0 \%)$ e CPO-D de 3,66 para o sexo feminino $(n=6$ $30,0 \%)$. Em relação às condições especiais de saúde, verificou-se que indivíduos com Síndrome de Down apresentaram o CPO-D mais elevado $(4,20)$, seguidos igualmente por indivíduos com paralisia cerebral $(3,00)$ e Síndrome do X-Frágil $(3,00)$ (Gráfico 1A e 1 B).

Constatou-se que o CPO-D em indivíduos com Síndrome do X-Frágil variou de 2 a 4, com média de 3,0. Para os alunos com Paralisia Cerebral a média foi 3,00 com mínimo de 0 e máximo de 7. No caso da Síndrome de Down, os valores variaram de 3 a 6 , com média de 4,20. Um único indivíduo, portador de Síndrome de West apresentou CPO-D igual a 0. Dessa forma, verificou-se que tanto o valor mínimo (0) quanto o valor máximo (7) foi encontrado em indivíduos com Paralisia Cerebral (Tabela 5).

\section{Discussão}

A realização da pesquisa simultaneamente nas APAEs dos Municípios de São Domingos/SC e Xaxim/SC teve como propósito ampliar o número de participantes, tendo em vista o pequeno número de alunos matriculados em cada cidade. A taxa de participação obtida, de $100 \%$, demonstrou o interesse nas questões relativas à saúde bucal e só foi possível através do apoio recebido pelas escolas, familiares e dos esforços em visitar cada um dos domicílios dos participantes.

A disponibilidade de produtos de higiene bucal, como escova de dente, creme dental e fio dental é imprescindível para os cuidados com a boca. O fato de $31,4 \%$ não dispor de fio dental sugere a existência de limitações econômicas, desinformação e até mesmo barreiras culturais. Sabe-se que famílias com melhores condições sociais possuem acesso mais fácil a tratamentos odontológicos, demonstrando que condições sociais se relacionam à cárie e às doenças periodontais ${ }^{17}$. Identificaram-se peculiaridades em cada domicílio, do ponto de vista econômico, social e cultural, as quais influenciaram decisivamente nas condições de saúde bucal dos alunos e demais moradores. Nesse sentido, é muito importante compreender como os determinantes sociais interferem na saúde bucal $\left.\right|^{9,10}$.

Tabela 4 - Distribuição do índice CPO-D nos escolares de 12 a 17 anos

\begin{tabular}{ccc}
\hline Variável & $\mathbf{n}$ & $\mathbf{\%}$ \\
\hline Valor do CPO-D & & \\
\hline 0 & 2 & 10,0 \\
1 & 1 & 5,0 \\
2 & 4 & 20,0 \\
3 & 3 & 15,0 \\
4 & 6 & 30,0 \\
5 & 1 & 5,0 \\
6 & 2 & 10,0 \\
7 & 1 & 5,0 \\
\hline Total & 20 & 100 \\
\hline
\end{tabular}

Fonte: Dos autores, 2016. 
Gráficos 1A e 1B- Valores do CPO-D dos 12 aos 17 anos por sexo e por condição especial de saúde
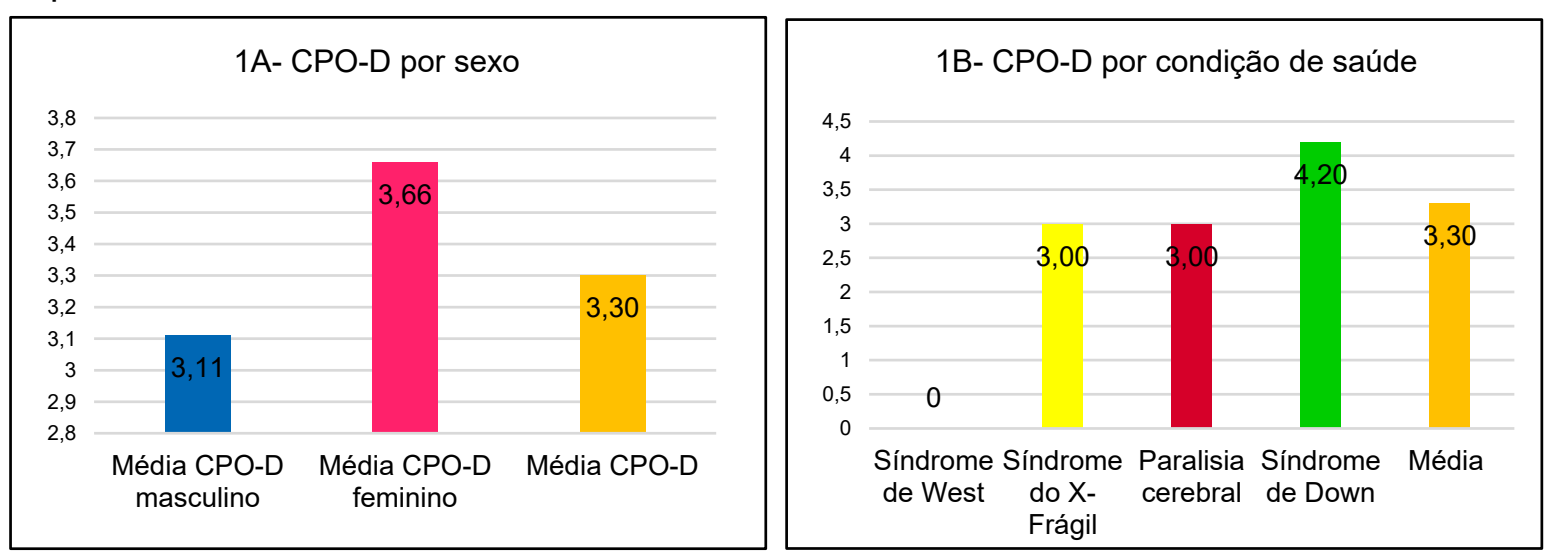

Fonte: Dos autores, 2017.

Tabela 5 - Valores mínimos, máximos e média do CPO-D dos 12 aos 17 anos por condição especial

\begin{tabular}{lcccc}
\hline \multicolumn{1}{c}{ Variável } & $\mathrm{n}$ & $\begin{array}{c}\text { CPO-D } \\
\text { mínimo }\end{array}$ & CPO-D máximo & CPO-D \\
\hline Condição de saúde especial & & & & \\
$\quad$ Síndrome do X-Frágil & 2 & 2 & 4 & $\mathbf{3 , 0 0}$ \\
Paralisia cerebral & 13 & 0 & 6 & $\mathbf{3 , 0 0}$ \\
Síndrome de Down & 5 & 3 & $\mathbf{4 , 2 0}$ \\
Síndrome de West & 0 & 0 & 0 & $\mathbf{0 , 0 0}$ \\
\hline$\quad$ Total & 20 & & & $\mathbf{3 , 3 0}$ \\
\hline
\end{tabular}

Fonte: Dos autores, 2017.

Neste estudo foi identificado maior número de alunos com paralisia cerebral (62,9\%). É de grande importância que os cirurgiões-dentistas conheçam as especificidades de pacientes com necessidades especiais em função de cada condição, com vistas ao cuidado integral e humanizado $0^{1,2,18,19}$.

No que se refere aos hábitos alimentares, constatou-se que embora $62,9 \%$ das crianças e adolescentes gostassem de alimentos doces e guloseimas, segundo $54,3 \%$ dos responsáveis, seu consumo era reduzido, o que sugere que parte dos pais busca, de alguma forma, oferecer alimentação compatível com a saúde. Contudo, boa parte os consumia entre as refeições principais $(31,4 \%)$.
Mesmo que $71,4 \%$ dos alunos gostassem de bebidas doces, $37,1 \%$ dos responsáveis informaram que eles raramente as ingeriam. Contudo, $45,7 \%$ tinha o costume de ingerir bebidas doces após as refeições.

Ainda, identificou-se que $31,4 \%$ dos pais costumavam acrescentar açúcares a frutas, vegetais, leite e outros alimentos de seus filhos, o que evidencia desinformação sobre os malefícios dos açúcares para a saúde bucal e geral.

Tais comportamentos alimentares favorecem o acúmulo de biofilme e a disponibilidade de ácidos na cavidade bucal, podendo ajudar a explicar os índices de biofilme e CPO-D encontrados. 
Os açúcares representam o principal fator dietético envolvido nas cáries dentárias ${ }^{20}$. Além disso, o seu consumo (incluindo bebidas açucaradas) compete com a ingestão de alimentos mais adequados sob o ponto de vista nutricional e está associado a doenças não transmissíveis como cárie dental e obesidade ${ }^{21}$. Por isso, é preciso restringir o consumo de açúcares. Vale destacar que a cárie dentária é uma doença de origem multifatorial associada ao consumo de açúcares, ao controle deficiente de biofilme, ao flúor e a fatores socioeconômicos ${ }^{22,23}$.

Quanto aos hábitos de higiene bucal, identificou-se que embora os pais tenham informação sobre a realização de três escovações diárias $(91,3 \%)$, na prática, menos da metade dos entrevistados $(48,5 \%)$ conseguia realizar esses cuidados. Considerando que parcela considerável $(28,6 \%)$ realizava única escovação diária, atenta-se para a necessidade que esse procedimento seja feito de forma bastante criteriosa.

Identificou-se limitado uso do fio dental, quando apenas $34,3 \%$ dos pais ou responsáveis informaram que os alunos o utilizam diariamente, embora para $65,7 \%$ ele devesse ser utilizado mais de duas vezes ao dia. Nesse sentido, verificou-se que existem limitações quanto ao nível de informação sobre o uso do fio dental.

Mesmo que muitas pessoas saibam que devem escovar os dentes três vezes ao dia e fazer uso do fio dental ao menos uma vez ao dia, mas não fazem disso um hábito. Como o biofilme dental está relacionado às principais doenças bucais, como a cárie, a gengivite e a periodontite ${ }^{24}$ é preciso removê-lo constantemente na cavidade bucal.

O uso do fio dental é tarefa difícil para uma parcela dos responsáveis, sendo um procedimento mais complexo de ser realizado, frente à escovação. Por isso, foi observado que muitos pais preferiram utilizar o momento de colaboração de seus filhos apenas para a escovação, deixando de lado o fio dental.
Verificou-se que o cirurgião-dentista teve papel importante no fornecimento de informações sobre os cuidados de saúde bucal para $77,1 \%$ dos respondentes. Na Cidade de Xaxim/SC a APAE contava com um cirurgião-dentista que realizava palestras e instruções de higiene oral para os pais semestralmente, justificando esses achados. De fato, a maioria dos entrevistados informou ter conhecimentos de como deve ser feita a higienização bucal de seus filhos, porém, relataram sentir dificuldade em realizar.

Assim, a elevada quantidade de biofilme constatada através dos exames bucais aponta para discordâncias entre o que os responsáveis informaram realizar em termos de escovações diárias. Acredita-se que as falhas na forma de realizar a escovação, com repercussões sobre a sua efetividade, podem ser explicadas pelos seguintes fatores: os pais não realizavam de forma eficaz e após as refeições; os pais não realizavam a higiene por acreditarem que não seria necessário e existiam dificuldades em lidar com as condições de cada criança e adolescente.

Vale lembrar, então, que indivíduos que dependem de outros para atividades diárias também demandam ajuda para o controle da higiene e da dieta. A diminuição na vigilância frente aos cuidados de higiene bucal pode ocasionar resistências e maiores dificuldades e estar associada ao aumento de doenças orais como cáries e gengivites ${ }^{15}$.

Em função do número limitado de indivíduos examinados, os valores do CPO-D encontrados referem-se à totalidade dos indivíduos, incluindo a faixa etária dos 12 aos 17 anos de idade, diferentemente dos levantamentos epidemiológicos em saúde bucal nacionais. O Índice CPO-D encontrado na amostra foi de 3,30. Considerando como parâmetro os dados do CPO-D identificados no Projeto SB Brasil $2010^{6}$, de 2,1 aos 12 anos e 4,2 aos 15-19 anos, o valor desse estudo para a amostra enquadra-se como intermediário.

Apenas dois alunos apresentaram CPO-D igual a zero. A maior parte dos indivíduos desse 
estudo apresentava valores de CPO-D entre 2,0 e 4,0 (juntos, $65,0 \%$ ), 5,0\% apresentaram CPO-D de 7,0 e outros $10,0 \%$ CPO-D de 6,0 .

As variações encontradas no Índice CPO-D em função do sexo apontaram para uma situação mais grave entre os indivíduos do sexo feminino, uma vez que houve valor mais elevado $(3,66)$ em um número menor de participantes $(n=6)$. Em relação à condição especial de saúde, foi contatado que indivíduos com Síndrome de Down possuíam piores condições bucais em relação à cárie dentária (CPO-D de 4,20). Mesmo assim, em função da amostra limitada, pela grande variação do número de indivíduos com cada condição, os achados não podem ser extrapolados. Embora essa pesquisa não tenha feito uma investigação mais minuciosa da condição social das famílias participantes, foi observado que nas famílias de melhores condições sociais o índice de CPO-D era menor. Assim, esses resultados servem de alerta para as consequências da cárie dentária no grupo estudado, confirmando a importância dos cuidados desde a família.

Sabe-se que o controle do biofilme e a adoção de hábitos alimentares saudáveis são importantes medidas preventivas para as doenças bucais mais prevalentes. Em função disso, é de extrema importância que aconteça o acompanhamento odontológico de crianças e adolescentes com necessidades especiais. Além disso, é preciso incluir os familiares, uma vez que o exemplo dos pais e/ou responsáveis e os conhecimentos acerca de saúde bucal exercem impacto direto no desenvolvimento dos hábitos da criança ${ }^{25}$. Assim, a atenção deve ser focada na família, nos seus hábitos de saúde bucal e estilos de vida, devendo aos pais serem motivados a melhorar a saúde bucal dessas crianças.

Mesmo que crianças com necessidades especiais tenham desenvolvimento motor inferior, ainda assim, podem desenvolver a capacidade de realizar a sua higienização oral. Defende-se, então, que os pais e os profissionais da Odontologia são corresponsáveis por auxiliar e supervisionar crianças e adolescentes com necessidades especiais a cuidarem da sua saúde bucal ${ }^{26}$. Para tanto, é preciso, antes de mais nada, conhecer as características, as especificidades e as potencialidades de cada indivíduo e sua rede de apoio familiar e social.

\section{Conclusão}

Crianças e adolescentes com necessidades especiais demandam cuidados específicos por parte dos pais, dos responsáveis e dos serviços educacionais e de saúde, sejam públicos ou privados, para a manutenção da saúde bucal. Muitas vezes, em função de sua condição de saúde, apresentam limitantes cognitivos e/ou motores, com impactos na autonomia para o autocuidado.

Este estudo identificou que a maioria dos alunos das APAEs de São Domingos/SC e Xaxim/ SC gostava de alimentos e bebidas doces e que uma parcela dos pais buscava limitar o seu consumo. Mesmo assim, verificou-se elevada ingestão de açúcares entre e após as refeições.

Quanto aos hábitos de higiene bucal, constatou-se que a quase totalidades dos pais revelou escovar os dentes das crianças e adolescentes ao menos uma vez por dia. Porém, o mesmo não foi verificado em relação ao uso do fio dental, quando nem todos os indivíduos o dispunham no domicílio.

Todos aos alunos apresentaram grande quantidade de biofilme visível. Quanto ao CPO-D para a faixa dos 12 aos 17 anos de idade, foi observada média de 3,3, com variação de 0 a 7 , o que sugere diferenças importantes em relação ao ataque da doença cárie dentária. Embora tenham sido verificadas diferenças em relação ao sexo e à condição especial de saúde, os achados não podem ser generalizados, em função do tamanho amostral.

Salienta-se que os pais e os responsáveis têm dificuldades para realizar a higiene bucal dos alunos, mesmo que disponham de informações sobre como fazer os procedimentos, evidenciando 


\section{a necessidade de acompanhamento odontológico} constante.

Os resultados obtidos possibilitaram compreender em profundidade as condições dos alunos nos municípios pesquisados. Sugere-se a realização de novos estudos, englobando maior número de indivíduos, de modo a elucidar como fatores determinantes e condições de saúde bucal podem ser manejados em função das especificidades dos pacientes portadores de necessidades especiais.

\section{REFERÊNCIAS}

1. Elias R. Odontologia para Pacientes com Necessidades Especiais - uma visão clínica. Santos: Editora Santos; 2007.

2. Haddad AS. Odontologia para pacientes com necessidades especiais. São Paulo: Editora Santos; 2007.

3. Lawton L. Providing dental care for special patients: tips for the general dentist. J Am Dent Assoc. 2002; 133(2):1666-70.

4. Carvalho EMC de., Araújo RPC de. A Saúde bucal em portadores de transtornos mentais e comportamentais. Pesqui Bras Odontopediatria Clín Integr. 2004; 4(1):6575.

5. Brasil. Ministério da Saúde. Projeto SB Brasil 2003: condições de saúde bucal da população brasileira 2002-2003: resultados principais. Brasília: Ministério da Saúde; 2004.

6. Brasil. Ministério da Saúde. Projeto SB Brasil 2010: pesquisa nacional de saúde bucal - resultados principais. Brasília: Ministério da Saúde; 2011.

7. Queiroz F de S, Rodrigues MML de F, Cordeiro Junior GA, Almeida ER. Avaliação das condições de saúde bucal de Portadores de Necessidades. Rev Odontol UNESP. 2014; 43(6):396-401.

8. Flório FM, Basting RT, Salvatto M V, Migliato KL. Saúde bucal em indivíduos portadores de múltiplas deficiências. RGO. 2007; 55(3):251-256.

9. Brasil. Ministério da Saúde. Diretrizes da política nacional de saúde bucal. Brasília: Ministério da Saúde; 2004.

10. Brasil. Ministério da Saúde. Cadernos de Atenção Básica - Saúde Bucal. Brasília: Ministério da Saúde; 2006.

11. Pregliasco F, Ottolina P, Mensi C, Carmagnola D, Giussani $\mathrm{F}$, Abati S, et al. Oral health profile in an institutionalized population of Italian adults with mental retardation. Spec Care Dent. 2001; 21(6):227-31.
12. Donell DO, Sheiham A, Wai YK. Dental findings in 4-,14- and 25-to 35-year-old Hong Kong residents with mental and physical disabilities. Spec Care Dent. 2002; 22(6):231-4.

13. Guaré RO, Ciamponi AL. Prevalence of periodontal disease in the primary dentition of children with cerebral palsy. J Dent Child. 2004; 71(1):27-32.

14. Naka S, Yamana A, Nakano K, Okawa R, Fujita K, Kojima $A$, et al. Distribution of periodontopathic bacterial species in Japanese children with developmental disabilities. BMC Oral Health. 2009; 9:24.

15. Skeie MS, Espelid I, Riordan PJ, Klock KS. Caries increment in children aged 3-5 years in relation to parents dental attitudes: Oslo, Norway 2002 to 2004 . Community Dent Oral Epidemiol. 2008; 36(5):441-50.

16. Organização Mundial da Saúde. Levantamento Epidemiológico Básico de Saúde Bucal- Manual de Instruções. $4^{\mathrm{a}}$ ed. Genebra: Organização Mundial da Saúde; 1997

17. Figueiredo RMO, Wassall T, Flório FM. Freqüência de impactos dos problemas de saúde bucal na qualidade de vida. RGO. 2006; 54(1):11-6.

18. De Camargo MAF, Antunes JLF. Untreated dental caries in children with cerebral palsy in the Brazilian context. Int J Paediatr Dent. 2008; 18(2):131-8.

19. Mugayar LRF. Pacientes portadores de necessidades especiais - manual de Odontologia e saúde oral. São Paulo: Pancast; 2000.

20. World Health Organization. Diet, nutrition and the prevention of chronic diseases: report of a joint WHO/FAO expert consultation. Geneva: World Heath Organization; 2003.

21. World Health Organization. Guideline: sugars intake for adults and children. Geneva: World Health Organization; 2015. 
22. Freire M do CM, Reis SCGB, Figueiredo N, Peres KG, Moreira R da S, Antunes JLF. Individual and contextual determinants of dental caries in Brazilian 12-year-olds in 2010. Rev Saúde Pública. 2014; 47(3):40-9.

23. Peres MA, Latorre MDRDO, Sheiham A, Peres KG, Barros FC, Hernandez PG, et al. Effects of Social and biological factors on dental caries in 6-years-old children: a cross sectional study nested in a birth cohort in Southern Brazil. Rev Bras Epidemiol. 2003; 6:293-306.

24. Casais PMM, Moreira IS, Moreira LGP, Oliveira MLL, Ribeiro ÉDP, Rapp GE. Placa bacteriana dental como um biofilme. Rev Fac Odontol Univ Fed Bahia. 2013; 43(1):61-6.
25. Costa C, Pereira M, Passadouro R, Spencer B. Higiene oral na criança. Acta Med Port. 2008; 21(5):467-74.

26. Moimaz SAS, Martins RJ, Delano F, Forte S. Oral hygiene practices, parents 'education level and dental caries pattern in 0 to 5 years-old children. Brazilian J Oral Sci. 2005; 4(14):778-82.

\section{CORRESPONDÊNCIA}

Ellem Fabiola Caregnato

Universidade Comunitária da Região de Chapecó

Rua Major Azambuja, 213, sala 211

São Domingos-SC, CEP: 89835-000

E-mail: ellem@unochapeco.edu.br 